
LA-UR-96- 2426
CONF-961017-- 4

\title{
Title: DISLOCATIONS AND MECHANICAL PROPERTIES OF SINGLE CRYSTAL NIOBIUM DISILICIDE
}

Author(s):

Submitted to:

Stuart A. Maloy, MST-4

Fuming Chu, CMS

John J Petrovic, MST-4

Terence E. Mitchell, CMS

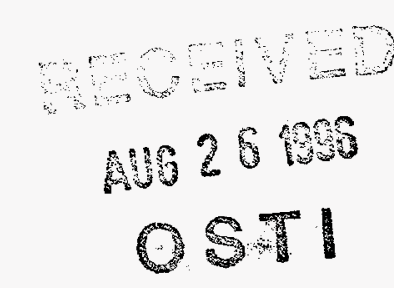

To be presented in Cincinnatti, $\mathrm{OH}$ at the TMS society Fall Meeting October 7-11, 1996

\section{Los Alamos}

NATIONAL LABORATOR

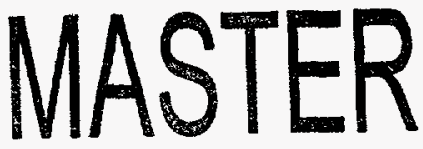

Los Alamos National Laboratory, an affirmative action/equal opportunity employer, is operated by the University of California for the U.S. Department of Energy under contract W-7405-ENG-36. By acceptance of this article, the publisher recognizes that the U.S. Government retains a nonexclusive, royalty-free license to publish or reproduce the published form of this contribution, or to allow others to do so, for U.S. Government purposes. The Los Alamos National Laboratory requests that the publisher identify this article as work performed under the auspices of the U.S. Department of Energy. 


\section{DISCLAIMER}

Portions of this document may be illegible in electronic image products. Images are produced from the best available original document. 


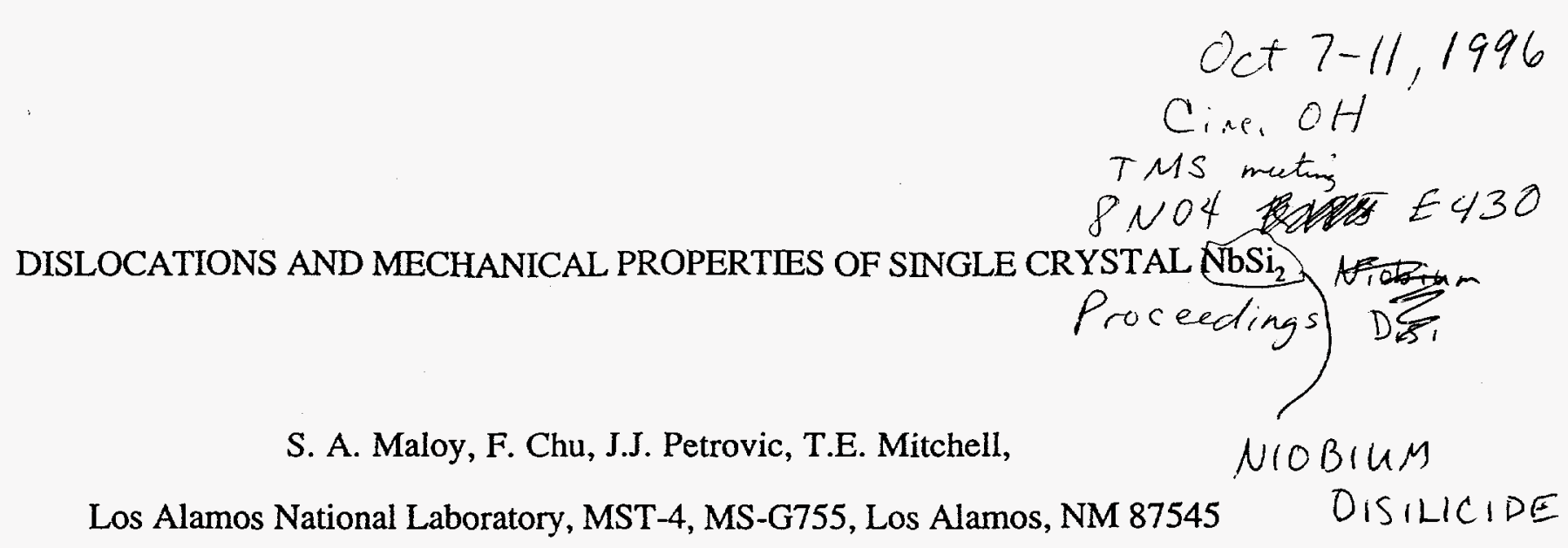

\begin{abstract}
The mechanical properties of single crystal $\mathrm{NbSi}_{2}$ have been investigated along [0001] and $45^{\circ}$ from [0001] toward [11 $\left.\overline{2} 0\right]$ using a Nikon QM-2 hot hardness tester from room temperature to $900^{\circ} \mathrm{C}$ in vacuum. The hardness along [0001] increases from room temperature to $300^{\circ} \mathrm{C}$ followed by a sharp decrease in hardness with temperature which is accompanied by a large uplift observed surrounding the indentations. Dislocations surrounding the indentations at room temperature and $300^{\circ} \mathrm{C}$ were analyzed using techniques in transmission electron microscopy to find slip by $\langle 10 \overline{1} 0\rangle$ dislocations at room temperature with a change in the active slip systems at $300^{\circ} \mathrm{C}$. The hardness along a direction $45^{\circ}$ from [0001] toward [11 $\left.2 \overline{2} 0\right]$ sharply decreases with increasing temperature above room temperature. Coarse slip lines surround the indentations referring to slip on the basal plane.
\end{abstract}

\title{
DISCLAIMER
}

This report was prepared as an account of work sponsored by an agency of the United States Government. Neither the United States Government nor any agency thereof, nor any of their employees, makes any warranty, express or implied, or assumes any legal liability or responsibility for the accuracy, completeness, or usefulness of any information, apparatus, product, or process disclosed, or represents that its use would not infringe privately owned rights. Reference herein to any specific commercial product, process, or service by trade name, trademark, manufacturer, or otherwise does not necessarily constitute or imply its endorsement, recommendation, or favoring by the United States Government or any agency thereof. The views and opinions of authors expressed herein do not necessarily state or reflect those of the United States Government or any agency thereof. 


\section{Introduction}

Because of growing interest in using silicides as high temperature structural materials, the mechanical properties of single crystal niobium disilicide are being investigated. $\mathrm{NbSi}_{2}$ is an attractive high temperature material because of its low density, $5.704 \mathrm{~g} / \mathrm{cc}$, and high melting point, $1920^{\circ} \mathrm{C}$. $\mathrm{NbSi}_{2}$ has the $\mathrm{C} 40$ hexagonal crystal structure with $\mathrm{c}=6.59 \mathrm{a}$ and $\mathrm{a}=4.79 \mathrm{a}$ and $\mathrm{c} / \mathrm{a}$ ratio of 1.374 , space group, $\mathrm{P} 6 / 222$ (see Fig. 1a). Fig. $1 \mathrm{~b}$ illustrating the basal plane in $\mathrm{NbSi}_{2}$ shows the shortest lattice direction to be $1 / 3<11 \overline{2} 0>, 4.79 a$. The next shortest lattice translation in the basal plane is $\langle 10 \overline{1} 0\rangle, 8.29 \AA$, which can break up into three collinear $1 / 3<10 \overline{1} 0>$ partials, $2.76 \mathfrak{a}$, separated by APB's. The shortest lattice direction with some c-axis component is [0001], 6.59æ followed by $1 / 3<11 \overline{2} 3>$, $8.15 a ̊$.

Some research has already been performed on the mechanical properties of single crystal $\mathrm{NbSi}_{2}$, although this research was limited to deformation along an orientation approximately $45^{\circ}$ from [0001] toward [11 $\overline{2} 0][1]$. Compression ductility was observed at temperatures down to room temperature and a yield anomaly was observed around $1350^{\circ} \mathrm{C}$. Slip traces referring to basal slip were observed after deformation.

This study looks at the mechanical properties of single crystal $\mathrm{NbSi}_{2}$ along [0001] and $45^{\circ}$ from [0001] toward [11 $\overline{2} 0]$ from room temperature to $1000^{\circ} \mathrm{C}$ using a hot hardness tester. Dislocations around indents are characterized to determine the active slip systems around indentations made at specific temperatures.

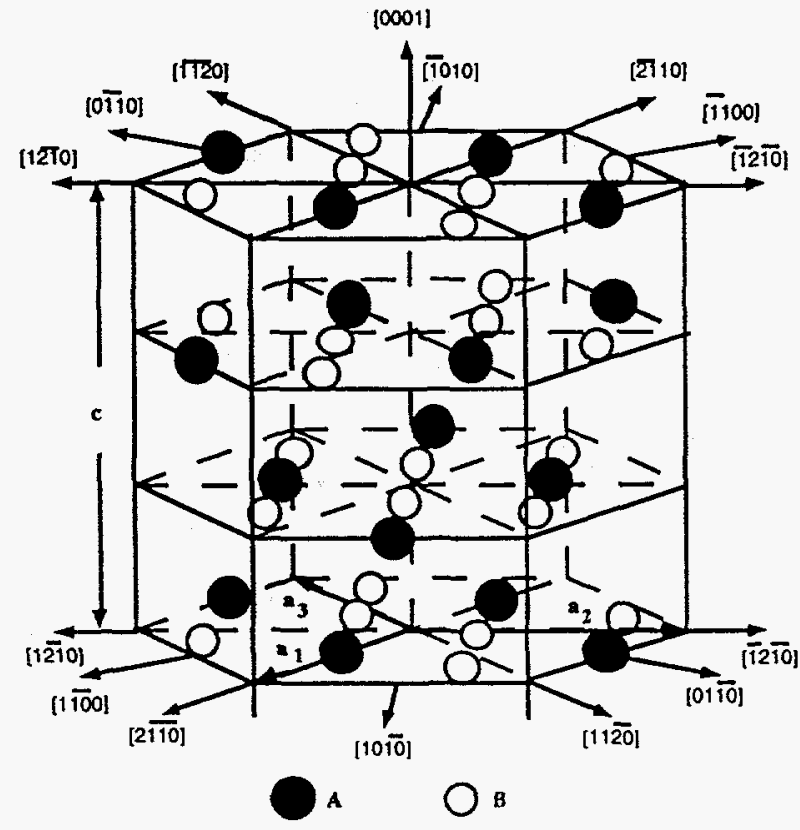

A

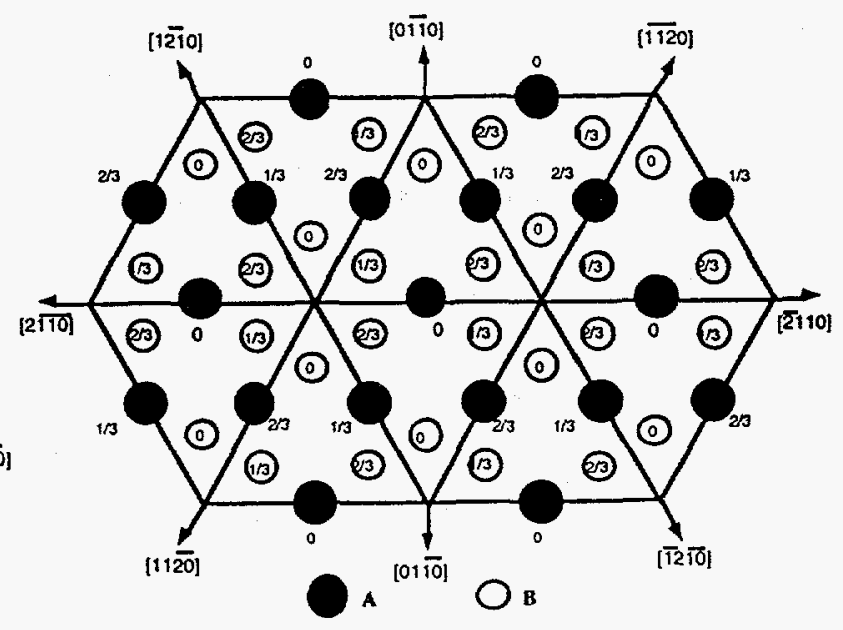

B

Figure 1 Schematic showing (a) the crystal structure of $\mathrm{NbSi}_{2}$ and (b) the [0001] plane of $\mathrm{NbSi}_{2}$. 
Single crystal $\mathrm{NbSi}_{2}$ was grown by J. Garrett using the Czochralski growth technique at McMaster University. Single crystals were oriented using a Laue back reflection X-ray machine along [0001] and $45^{\circ}$ from [0001] toward $<11 \overline{2} 0>$. Foils were ion milled to electron transparency to analyze the initial dislocation density in the starting material. Samples were cut into parallelepipeds approximately $5 \times 5 \times 10 \mathrm{~mm}$ in size. One side was polished down to $1 \mu \mathrm{m}$ diamond paste. A Nikon QM-2 hot hardness tester was used to determine the hardness of single crystal $\mathrm{NbSi}_{2}$ in vacuum from room temperature to $1000^{\circ} \mathrm{C}$ by measuring five indentations at each temperature. Slip traces and cracks around indentations were observed using a JEOL 6300FVX field emission scanning electron microscope at $25 \mathrm{kV}$. Thin foils were back thinned around indentations using a Gatan ion mill. Dislocations around indentations were analyzed by performing g•b and trace analyses with a Philips CM30 TEM.

\section{$\underline{\text { Results }}$}

\section{$45^{\circ}$ from $[0001]$ toward $[11 \overline{2} \underline{0]}$}

The hardness measured along $45^{\circ}$ from [0001] toward [11 $\left.\overline{2} 0\right]$ is shown in Fig. 2. The hardness sharply decreases with increasing temperature from room temperature up to $900^{\circ} \mathrm{C}$. Hardness was not measured above $900^{\circ} \mathrm{C}$ as the indenter reacted with the specimen. Coarse slip lines on the basal plane and cracking were observed around all indentations at all temperatures as shown in Fig. 3 for a typical indentation performed at $900^{\circ} \mathrm{C}$. Knoop indentation was also

performed at room temperature with the long direction of the indenter oriented parallel to [1 $\overline{1} 00]$ and perpendicular to $[1 \overline{100}$. No slip lines on the basal plane or cracks around the indentation were observed when the long direction of the indenter was oriented perpendicular to [10 $\overline{1} 0]$ while coarse slip lines on the basal plane and cracks were observed around indentations performed with the indenter oriented parallel to [1 $\overline{1} 00]$ (see Fig. 4). The hardness was highest when the indenter was oriented parallel to [1 $\overline{1} 00]\left(683 \pm 5 \mathrm{~kg} / \mathrm{mm}^{2}\right)$ and softest $\left(642 \pm 16 \mathrm{~kg} / \mathrm{mm}^{2}\right)$ when indented perpendicular to $[1 \overline{1} 00]$.

[0001]

The variation of hardness along [0001] from room temperature to $700^{\circ} \mathrm{C}$ is shown in Fig. 2. The hardness anomalously increases with temperature up from 100 to $300^{\circ} \mathrm{C}$ followed by a decrease with temperature up to $700^{\circ} \mathrm{C}$. The anomolous increase in hardness observed starting at $300^{\circ} \mathrm{C}$ is accompanied a marked change in the appearance of the hardness indentation starting at 


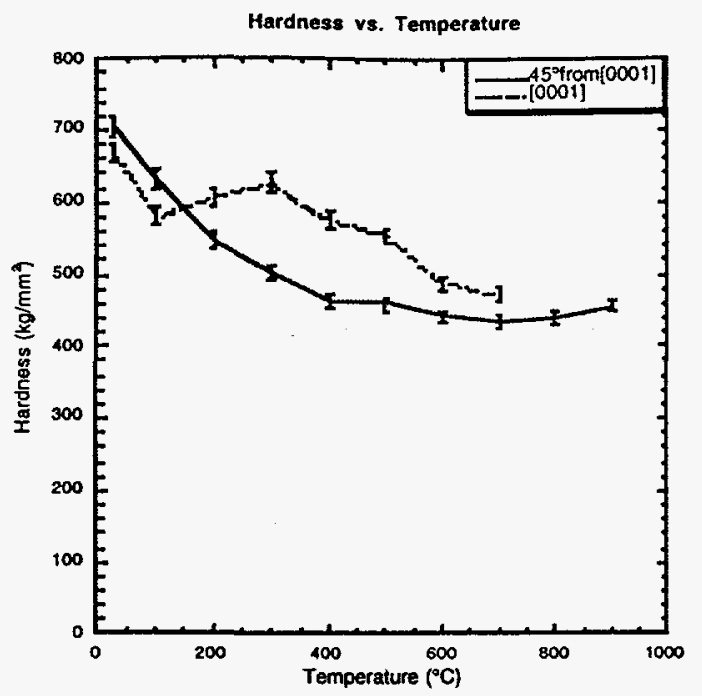

Figure 2 Graph showing hardness vs. temperature for single crystal $\mathrm{NbSi}_{2}$ along two different orientations.
Figure 3 Optical micrograph showing an indentation performed at $900^{\circ} \mathrm{C}$ along a direction $45^{\circ}$ from [0001] toward [11 20 ]

A

B

Figure 4 Optical micrographs showing Knoop indentations performed in a direction $45^{\circ}$ from [0001] toward $\langle 11 \overline{2} 0\rangle$ with the long axis of the indenter (a) parallel to [1 $\overline{1} 00]$ and (b) perpendicular to $[1 \overline{1} 00]$. 
$200^{\circ} \mathrm{C}$. Fig. 5 shows an overall optical micrograph of the hardness indentations from room temperature to $500^{\circ} \mathrm{C}$. There is an obvious change in the appearance of the uplift around the indent at $200^{\circ} \mathrm{C}$ from a gradual uplift at temperatures below $200^{\circ} \mathrm{C}$ to a distinct hexagonal shaped uplift at $200^{\circ} \mathrm{C}$ and above.

This anomaly was studied further using scanning electron microscopy. The results reveal a difference in cracking and the appearance of slip lines from observing indents performed below and above $300^{\circ} \mathrm{C}$ (see figure $6 \mathrm{a}$ and b). Cracking was random around the indents below $100^{\circ} \mathrm{C}$ while it changed to cracking inside the indentation which was parallel to the basal plane at $100^{\circ} \mathrm{C}$ and above. Slip traces were observed in the bottom of indents performed at room temperature but not at any other temperatures. The slip traces were observed in a triangular pattern.

To analyze the deformation mechanisms active around indentations at room temperature and $300^{\circ} \mathrm{C}$, TEM foils were back-thinned around indents performed at room temperature and $300^{\circ} \mathrm{C}$. The g.b analysis in Fig. 7a-d reveals two sets of dislocations around an indentation performed at room temperature. The first set (labeled A in Fig. 7a) go out of contrast when imaged with $g=(1 \overline{2} 11)$ and $g=(1 \overline{2} 10)$. Therefore, they have [10 $\overline{1} 0]$ Burgers vectors. The second set (labeled $B$ in Fig. 7a) go out of contrast with $g=(11 \overline{2} 0)$ and $g=(11 \overline{2} 1)$. Therefore, they have [1 $\overline{1} 00]$ Burgers vectors. Slip trace analyses on these sets of dislocations revealed that dislocations labeled A have a $[10 \overline{1} 0]$ line direction while those labeled $B$ have a $[1 \overline{1} 00]$ line direction making them pure screw dislocations

Dislocations around indentations performed at $300^{\circ} \mathrm{C}$ were also observed. The dislocations were observed using many different g-vectors, although they were only clearly invisible when imaged with $g=(01 \overrightarrow{1} 0)$ (labeled $A$ in Fig. $8 a)$ and $g=(10 \overline{1} 0)$ (labeled B in Fig. 8a). The

Figure 5 Optical micrograph showing indentations performed along [0001] from room temperature to $500^{\circ} \mathrm{C}$. 
Figure 6 Scanning electron micrograph showing indentations performed along [0001] at (a) room temperature and (b) $200^{\circ} \mathrm{C}$.

Figure 7 Bright field transmission electron micrographs showing dislocations around an indentation performed at room temperature along [0001]. Imaged with (a) $g=(1 \overline{2} 11)$, (b) $\mathrm{g}=(1 \overline{2} 10),(\mathrm{c}) \mathrm{g}=(11 \overline{2} 0)$ and $(\mathrm{d}) \mathrm{g}=(11 \overline{2} 1)$. 
Figure 8 Bright field transmission electron micrographs showing dislocations around an indentation performed at $300^{\circ} \mathrm{C}$ along [0001]. Imaged with (a) $g=(01 \overline{10})$ and (b) $g=(10 \overline{1} 0)$.

dislocations were clearly visible when imaged with $<11 \overline{2} 0>$ g-vectors ruling out the possibility of the dislocations having $a<10 \overline{1} 0>$ Burgers vector.

\section{Discussion}

\section{$45^{\circ}$ from [0001] toward [11 20$]$}

The hardness results along a direction $45^{\circ}$ from [0001] toward [11 $\left.\overline{2} 0\right]$ show the ease of basal slip in $\mathrm{NbSi}_{2}$. The coarse slip bands on the [0001] plane reveal that nucleation of slip is difficult while dislocation glide on the basal plane is easy. This is not surprising because the basal plane is the densest plane in $\mathrm{NbSi}_{2}$. The anisotropy in hardness observed from the Knoop indentations also confirms the ease of slip on the basal plane, because the hardness was higher when no basal slip traces were observed and softer when numerous basal slip traces were observed. Future work will determine the active slip systems around Knoop indentations in each case using transmission electron microscopy. It is surprising that a high degree of cracking accompanies indentations exhibiting basal slip. This may result from high stresses built up between the coarse slip bands.

In comparing our hardness results along a direction $45^{\circ}$ from [0001] toward [11 $\left.\overline{2} 0\right]$ to compression results measured by Umakoshi et al.[1], one can see a strong agreement as they observe basal slip after deformation at all temperatures. Future work will investigate the hardness at higher temperatures up to $1400^{\circ} \mathrm{C}$ where they reported a yield anomaly.

[0001]

An interesting anomaly in the hardness vs. temperature curve is observed for deformation in the [0001] orientation. This anomaly is accompanied by a change in the uplift surrounding the 
indents from gradual to a distinct uplift with a hexagonal shape. The change in cracking from a random crack pattern surrounding the indent to cracking within the indent on the basal plane suggests that the uplift is associated with cracking on the basal plane.

The results of the dislocation analyses show that there is a change in slip system associated with the anomaly. Slip at lower temperatures occurs by $<10 \overline{1} 0>$ Burgers vectors while slip at higher temperatures occurs by either $1 / 3<11 \overline{2} 3>$ or $1 / 3<11 \overline{2} 0>$ Burgers vectors. Further TEM analyses will resolve this active slip system at higher temperatures.

\section{Conclusions}

1) The hardness of single crystal $\mathrm{NbSi}_{2}$ has been determined from room temperature to $900^{\circ} \mathrm{C}$ along a direction $45^{\circ}$ from [0001] toward [11 $\left.\overline{2} 0\right]$ and along [0001].

2) Basal slip is observed around all indentations performed in a direction $45^{\circ}$ from [0001] toward [11 $\overline{2} 0]$.

3) The hardness measured along [0001] anomalously increases with temperature from $100^{\circ} \mathrm{C}$ peaking at $300^{\circ} \mathrm{C}$.

4) Dislocations around indents performed at room temperature along [0001] have [10 $\overrightarrow{1} 0]$ Burgers vectors while a change in slip systems is observed at $300^{\circ} \mathrm{C}$.

5) Cracking on the basal plane is observed within indents performed along [0001] at $100^{\circ} \mathrm{C}$ and above.

Acknowledgment:

This work was performed under the auspices of the U.S. Department of Energy.

\section{Reference}

1. Y. Umakoshi, T. Nakashima, T. Nakano, and E. Yanagisawa, "Plastic Behavior and Deformation Structure of Silicide Single Crystals with Transition Metals at High Temperatures", in High Temperature Silicides and Refractory Alloys, vol. 322, ed. C.L. Briant, J.J. Petrovic, B.P. Bewlay, A.K. Vasudevan, and H.A. Lipsitt, (Materials Research Society, 1993), 9-20. 